\title{
Engineering a digital future
}

\author{
This is the inaugural address of Tim Broyd, who became the 152nd president \\ of the Institution of Civil Engineers on 1 November 2016.
}

Innovation and technological advances have been at the heart of the Institution of Civil Engineers (ICE) for years, and they are the themes on which my career has been based.

This address allows me to set out my thoughts on a subject about which I am passionate: the key challenges and opportunities that face society, and how the civil engineering profession, supported by ICE, must change to be up to task of tackling them.

I will set out how digital engineering can transform people's lives, and how this agenda can help civil engineers to deliver, on time, at reduced cost and with a quality and precision that changes the way they operate and manage truly smart infrastructure.

\section{Defining digital engineering}

'Digital' can mean different things to different people. I am talking about a world where

- civil engineers can provide their customers with the same level and reliability of service from infrastructure that society has come to expect from the likes of Amazon, Google and Uber

- infrastructure brings economic prosperity, improves living standards and provides a better quality of life to the billions of people for whom reliable, clean drinking water is still an aspiration

- society will be able to demand and receive a level of service and will be absolutely confident it will receive that service

- technology will enable civil engineers to understand in real time how assets are performing and be able to intervene to maximise value for money

- civil engineers lead the way in innovative thinking and find new ways of adding value.
So when I say the civil engineering profession must engineer a digital future, I mean much more than just using existing technologies to keep doing what it is already doing but faster and cheaper. I mean civil engineers must engineer for themselves a complete transformation in the way they think about infrastructure and professional practices.

This transformation must address the issues the public cares about. The profession must explain to members of the public, in plain language, how it will meet their personal needs and concerns. I know it sounds like a very big ask, and so it should be. As a profession, civil engineers are ambitious, they aim high.

But the profession must also recognise that society has entered a new industrial revolution. If civil engineers are what they claim to be, they must get ahead and move beyond simply responding to events. They must forecast what society needs and then provide it.

\section{Building on success}

The profession has many positives to build on - indeed, civil engineers have already started on the digital journey. The rise of artificial intelligence and vast pools of data are leading to better decision-making. Advances in technology, computing power and just the sheer volume of available data are transforming how infrastructure is operated and what it can do for the public.

The advent of smart highways, smart meters and the 'internet of things' is changing expectations of what physical infrastructure can, and should, do for society. Autonomous vehicles are becoming a reality and look set to shape the future of mobility and mass transit, and potentially even the fabric of cities and towns.
Civil engineers are already committed to radical improvements in time and quality of projects. This commitment was driven by one of my presidential predecessors, Peter Hansford, during his time as the UK government's chief construction advisor.

By adopting building information modelling (BIM), in conjunction with lean and agile technologies, the profession is already going some way to reducing the capital cost of projects, approximately $20 \%$ according to the government (Figure 1). The mandate for BIM shows what can be achieved when government and industry work together.

But as ever, there is further to go. Currently, BIM is mainly used for central government procurement, so the next step must be to ensure that more local authorities and private clients insist on its use.

BIM is a useful case study of how technology can support collaboration, save time and improve our ability to deliver. It is an example of innovation, however, not of invention. There is an important difference. Civil engineers do not always need to invent new technologies or business models; but they do always need to be innovative in how they deploy existing knowledge.

The changes are global. Look at the maglev trains in China and Japan,

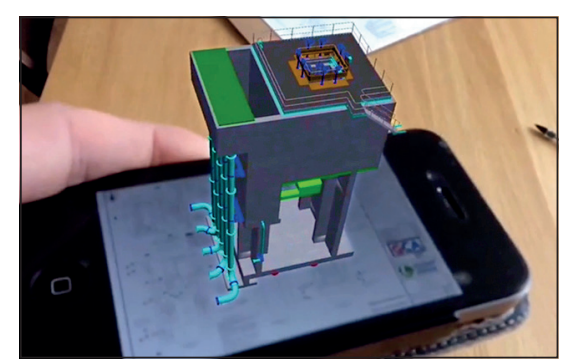

Figure 1. BIM is a classic example of how civil engineers can be more innovative 
the grace and elegance of the links between Hong Kong and Macau, and the new delivery models unlocked by Australia and New Zealand's approach to long-term planning.

In London with Crossrail, the adoption of new technologies and use of data have enabled a whole new railway line to be built under the middle of the city, with minimal disruption and close integration with other railway services. In turn, it will add 10\% extra capacity to London's overcrowded rail network and unlock billions of pounds of economic growth.

The same expansive thinking is going on across the country. BIM was used in the design and construction of the new Alder Hey Children's Hospital in Liverpool - the recent recipient of the Prime Minister's Better Building Award at the 2016 British Construction Industry Awards (Figure 2). It allowed greater integration of the building as a whole entity, across the whole supply chain, and streamlined coordination between design and engineering teams. As a result, it is one of the fastest-built a real difference to the lives of the children and families who depend on it.

Despite the successes, BIM has so far only really been used to help capital delivery. If its use can be moved into the operational phase, we have a real opportunity radically to improve performance over the whole life of hospitals to date in the UK, making

an asset. For me, understanding and improving how infrastructure is performing is what is really important, and what will make the biggest difference.

I was honoured to be asked by the UK government to pull together a strategy for the next generation of BIM. I want to extend BIM into operational stages, by using increasingly large volumes of data to measure the performance of infrastructure.

A recent report by KPMG (2016) demonstrated that construction companies and project owners which invest in disruptive, digital technologies should enjoy a step-change in performance. But unfortunately when it came to technological innovation, just $8 \%$ of global construction companies were considered to be 'visionary'. A total of $69 \%$ were considered 'behind the curve'.

I do believe, however, that it is possible to achieve the goal of gathering real-time information on how assets are performing and feed that back to asset managers - or even to customers directly - opening up the prospect of delivering a service to a specified level of performance. That is where the true value lies for society.

In plain English, it will mean making trains run faster, cheaper, more frequently and more reliably. It will mean making sure the lights never go out and that people can afford their

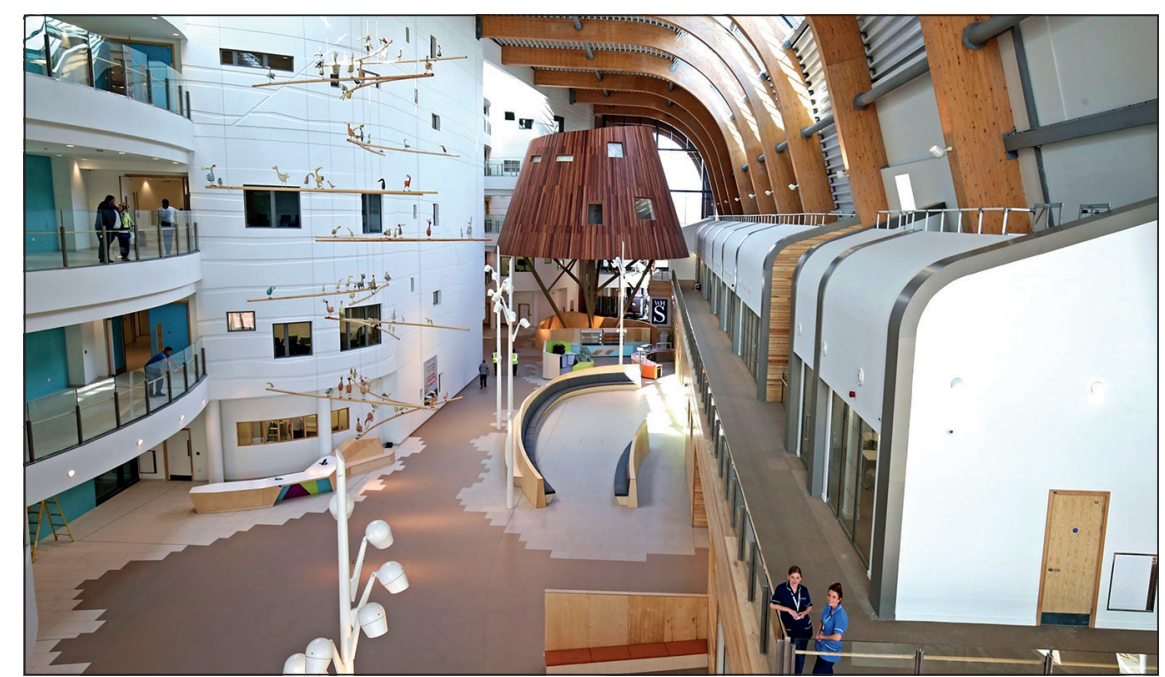

Figure 2. BIM enabled rapid delivery of Alder Hey Children's Hospital in Liverpool energy bills. The UK BIM Alliance, led by ICE fellow Anne Kemp, will provide the necessary leadership on this very important issue and will help to realise the full benefits of the technology.

\section{Modernise or die}

Civil engineers also need to take a long, hard and honest look at themselves. The Construction Leadership Council, co-chaired by ICE vice-president Andrew Wolstenholme, has published the Farmer Review, or to use its more provocative subtitle, 'Modernise or Die' (Farmer, 2016).

It painted a bleak picture of the UK construction industry, parts of which are locked into what it called a survivalist mode, rooted in short-termism, afflicted by low productivity, low profitability and low innovation. I do not agree with everything in the report - there is much to be optimistic about in the industry. But Farmer is right when he says leaders of construction professions need to commit, and I mean really commit, to a radical transformation of how the construction industry goes about its business. He is also right that technology and innovation are key to delivering these changes.

McKinsey's recent report on infrastructure productivity (Dobbs et al., 2013) said that contractors should be encouraged to use advanced techniques from manufacturing, such as prefabrication and modularisation. While a lot of progress has been made in these areas in recent years, there is still much more that we can do, and to a good end. The prize is huge. The McKinsey report argues that these measures, among many others, could globally help save US\$1 trillion a year and help head off delays and overruns in projects.

There is much to be learnt from other sectors, such as aerospace and manufacturing. Just look at how materials used in airframe construction have changed; how aviation engineers' business models have been changed to meet customer, not industry, needs; and how logistical engineering has transformed manufacturing.

While civil engineers need to borrow innovations from other sectors, they 
must also remember civil engineering is not the same as these sectors in every way. Developing a faster jet or more efficient car is different from protecting homes from flooding or keeping the traffic moving.

Other industries do seem to find it easier to take risks and try out new technologies. Perhaps this is because there is not an entire system failure at risk in doing so; one that could affect whole cities, taxpayers' money or a politician's chances of being re-elected. Civil engineering is perceived as a riskaverse sector and, in one respect, this is understandable. The profession cannot put the public at risk by cutting corners.

Civil engineers need to find out how to take more risks given these constraints. They need to take more risks in supporting research and development - and get better at exploiting the results of research that is already carried out (Figure 3). There is some excellent work in the UK Collaboratorium for Research in Infrastructure \& Cities, a UKgovernment-funded programme that is delivering a new generation of infrastructure capital research facilities in leading UK universities.

But civil engineers still need to find ways to test new business models and new technologies in a safe environment. They need to look more closely at vertical integration. While I am not suggesting monoliths, civil engineers do need to think seriously about some of the benefits these changes could bring for clients and end-users.

They must find new ways of exploiting and sharing knowledge, and new ways to inspire trust. They need to create more opportunities to drive the innovation agenda and to do so harder and faster than they have done to date.

I have spent the majority of my career in innovation, sustainability and knowledge management in the infrastructure sector. Over the years I have worked extensively on the development of digital engineering techniques, and on advanced, holistic techniques for assessing the long-term sustainability of infrastructure assets.

The thread linking virtually all of my work has been trying to understand the appropriate use of digital technology

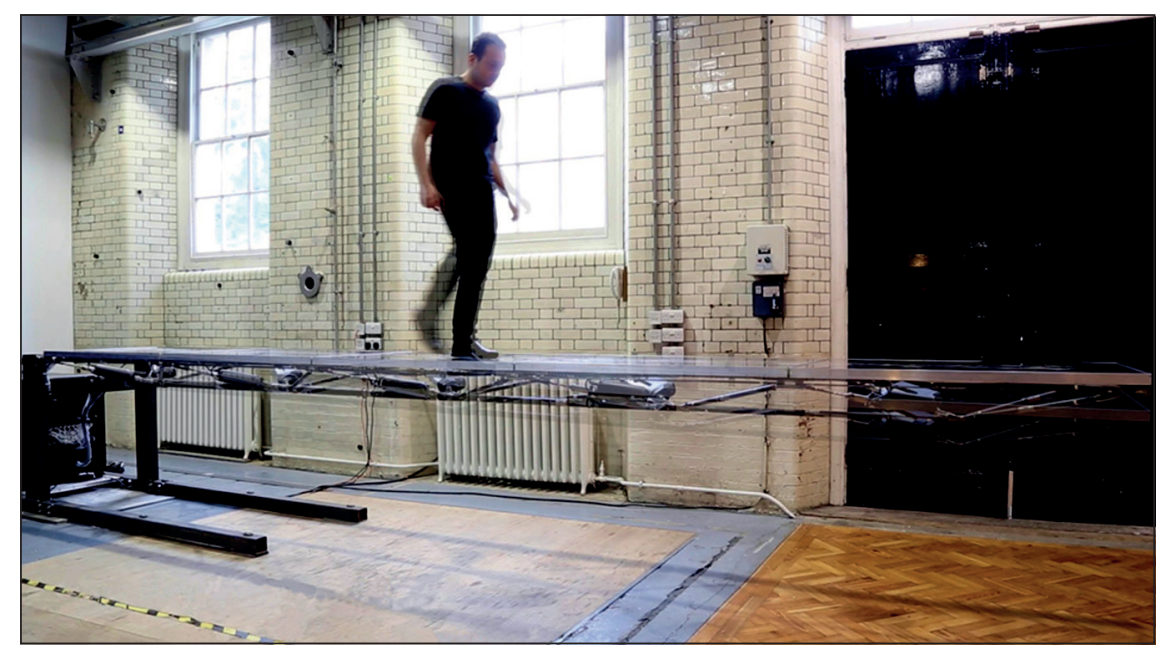

Figure 3. Expedition's adaptive truss was developed with UCL and ICE support

and digital techniques, and how to integrate technology into infrastructure systems to give the public the best possible outcome.

Early in my career, as research and innovation director at Atkins I was invited to step into a totally new role. Research and development was then a poorly understood area in the industry. So I started with a blank sheet of paper for a job specification. Filling it in required a great deal of trust and collaboration - a culture change in the firm.

The same was true when I became the first chief executive officer of Ciria and later as Halcrow's research and development director. In all these organisations we realised we must change ourselves, because it would be good for us, good for the people who work for us and, ultimately, good for the whole of society. As an industry we had become too used to being provoked into change at short notice by being prodded with a long, pointy stick by government.

Research and development - which has innovation at its core - is about removing the need for the stick. It is about managing the future, by inventing your own future. I never did fill the piece of paper. And that is how I think it should be. The very essence of innovation is that it continually evolves to meet the changing needs of each organisation and the profession as a whole.
Thankfully, the profession has come a long way since the 1970 s when it used slide rules and seven-figure logarithms. But changes to date are far less radical than they could be. Civil engineers need an even greater cultural shift than I was part of, as well as advances in technology. Civil engineers cannot continue to constrain thinking or to encumber the profession with outdated processes and procedures.

There is now little place in the profession for the intellectually lazy or the unenquiring mind. The key to effecting a change in culture, I believe, is putting the customer first in all that civil engineers do. The profession's commitment to innovation must be wedded to a commitment to the public The two go hand in hand.

The older generation must also make an even greater commitment to the next generation. The great civil engineers of the past were successful because they had in mind a vision for how life for the public could be better. Examples include Joseph Bazalgette's sewers, designed to relieve London of its debilitating health problems, and Stephenson's first ever steam railway line between Liverpool and Manchester, built to achieve cheaper and quicker transport of goods and passengers.

The Liverpool-Manchester line was often described as the 'Grand British Experimental Railway', its success or 
failure was key to plans for all future railways. Imagine if they decided it was too risky to build. Certainly the project faced opposition from the landowners over whose land it was proposed to pass - it seems like some things never change.

In both cases, and in many others, the engineers had an acute sense and understanding of what they could deliver for the public. That was true then and it is true now. It can be seen in the great civil engineers of our time. They have in mind an understanding of what they are trying to achieve, what the problem is they are trying to solve and, most importantly, what benefit this would bring to the public.

It is known from recent research that the public are more supportive of the need for better infrastructure than is sometimes assumed. But, rightfully, they want to understand what it means to them, how it relates to them and how their lives will be better. Will it give them more employment opportunities? Can they visit places their family has never been to before? Will their children be safer? Can they afford to buy a home? These are the questions for which civil engineers must show they have answers.

A digital transformation will help the profession to meet these challenges. Fundamentally, its goal is to make people's lives better. Civil engineers need to shift their thinking to what people want and what their society needs to thrive. And they need to create the space where they can innovate in order to meet these needs.

\section{Today's golden age of infrastructure}

What gives me reason to be optimistic is that I believe there is now a golden age of infrastructure delivery in Britain. Civil engineers are getting much better at delivering infrastructure, on time and on budget. The UK is now seen as a country where projects are managed properly - a real step-change from 30 years ago - and each project is getting better than the last.

Clients from all nations look to the UK for best practice on delivering large-scale programmes. Students from around the world are coming to the UK for specialist education on how to deliver major projects. UCL's masters' programme covering project and programme management is now substantially oversubscribed, with a significant majority of applications coming from overseas. This is a key strength - a marketable and exportable commodity - and must not be talked down.

Clients have never before adopted such a collaborative approach. They have never before shared so much knowledge and experience among themselves and, perhaps more importantly, with the outside world. ICE has helped to drive this change.

The Institution's suite of NEC3 contracts has been instrumental in facilitating greater collaboration and breaking down the barriers created by more traditional, transactional approaches. The Infrastructure Client Group - supported by ICE and the Infrastructure and Projects Authority work tirelessly to improve the efficiency of the construction sector and help deliver major cost savings. Consequently, this has had a demonstrable, positive impact on the service the construction sector offers the public.

I believe that the use of digital technology is making a big contribution to the golden age. While there is no 'silver bullet' that guarantees projects are delivered better, the application of digital tools, techniques and technologies - and just a digital mindset - will take civil engineering to the next level. It will help make sure this golden age lasts long into the twenty-first century.

The civil engineering profession must embrace the rise and importance of new digital technologies and the profound changes they will bring. As the voice of infrastructure and as part of its royal charter, ICE will drive and support this vision for a digital future (Figure 4).

The ICE's next flagship policy report in its 'State of the Nation' series, due to be launched in spring 2017, will focus on digital engineering. The report will look at the implications of digital on civil engineering and all infrastructure sectors, and therefore for society. It will examine the potential for radically improved services and outcomes and the interventions from both government and industry that are needed.

The report will build upon findings that have come through ICE's industry transformation thought-leadership programme: emerging thinking from around the world on how to deliver and operate high-performing infrastructure.

I have argued that digital is not just solely about technology. It is also about having a modern mindset. This leads me on to two other issues, which I believe are critical to the profession's future success.

\section{A broad church}

ICE has always prided itself on being a 'broad church'. I want it to be a home and voice for everyone contributing to the engineering, construction, builtenvironment and infrastructure sectors. Increasingly this includes professionals in firms that we would not normally assume are part of the infrastructure debate - engineers at companies like Google, IBM or Siemens, as well as colleagues in other professions at firms like KPMG and Pinsent Masons, who work alongside civil engineers to deliver more for the public. Civil engineers should join with these professionals to include their ideas and expertise in their work.

The National Needs Assessment report, which ICE presented to the chief secretary to the UK Treasury in October 2016 (ICE, 2016), is an excellent example of the Institution's broadchurch approach to solving some of the

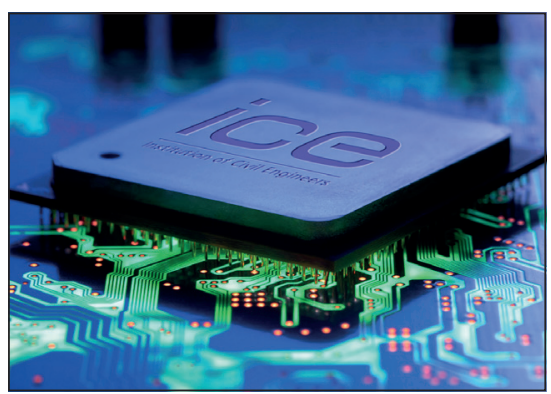

Figure 4. Digital technology will be at the heart of ICE's activities in 2017 
UK's big national challenges. The report also showed how important digital engineering will be for the future of infrastructure networks.

Each industrial revolution has been based around a transformation of infrastructure. And an infrastructure revolution is under way now, which is enabling smarter delivery and better use of services. The National Needs Assessment showed that the future will not always be about building more things, but it will be about applying technology to use infrastructure more efficiently.

ICE has also used a broad-church approach when making the case for infrastructure at a time of great change - as the government negotiates Britain's withdrawal from the European Union. It is still unclear what 'Brexit' will mean for the construction sector, and this is not just a concern for civil engineers in the UK. It was an issue that came through strongly during my recent visits to Malaysia and the Middle East.

ICE's pan-industry Brexit Infrastructure Group, and its support for the Royal Academy of Engineering's parallel work across all engineering disciplines, has gathered wide-ranging expertise with the aim of better informing the UK's negotiations. Politicians and officials must be equipped with the facts on the challenges and opportunities for the sector.

Civil engineers have a responsibility as professionals to offer support and advice. I was inspired by the way the industry has come together to work for the common good. And as part of this debate it should be very clear that, fundamentally, civil engineering is a global industry with global supply chains. It must therefore remain globally competitive

The UK should not walk away from practices which create a common framework for trade, and help civil engineers to do business - not only across Europe, but all over the world. ICE has been supporting the development of infrastructure around the world for over 200 years. There is no reason why this should change.

Civil engineering's record on transparency and fair procurement processes signifies the strength of the UK market. I see no reason why this will not continue. ICE's professional qualifications are globally recognised. This will not change. While the profession recognises that there is capacity challenge now, it also needs to be confident that it can attract the right skills in the future.

The economic benefits of the civil engineering industry and of effective infrastructure are well established. Infrastructure boosts economic growth, rebalances the economy, creates jobs, regenerates communities, connects people and places, and underpins environmental sustainability. So now, more than ever, the case for infrastructure must continue to be made. And that case has been and will be made by ICE and its members.

\section{Communicating the value of civil engineering}

Another way civil engineers can benefit society is by communicating the value of civil engineering and changing the perception of what a civil engineer does. As part of the refurbishment of the Institution's headquarters building in London, ICE has created an 'Infrastructure Learning Hub' - a new exhibition space to showcase the profession's work to the public. This has been made possible by generous donations from many and, on behalf of ICE, I would like to offer sincerest thanks and gratitude.

The first exhibition, on bridges, tells the story of civil engineering through some of the profession's most iconic creations. This will be the first of many different types of stories being told about the contribution that civil engineers make to society.

The exhibition also includes the world's longest Lego bridge, with the aim of inspiring the next generation of civil engineers. There have already been 1500 people through ICE's doors to see it, and over 10000 views online.

One other area of ICE that not many people know about is the Benevolent Fund, a charitable arm that supports civil engineers from all walks of life who find themselves in times of hardship and distress. It is the profession's way of giving back to those who help to shape the world. Programmes such as these are just a few of the ways the ICE pools its resources to support civil engineers, and promote all the benefits they bring.

The profession also needs to change the perception of who a civil engineer is. Women represent $12 \%$ of ICE's total membership. Female applications are rising slowly, with $21 \%$ of UK students and new graduates being women (Figure 5). This year, 13 members and fellows of ICE featured in The Daily Telegraph (2016) top 50 women in engineering poll.

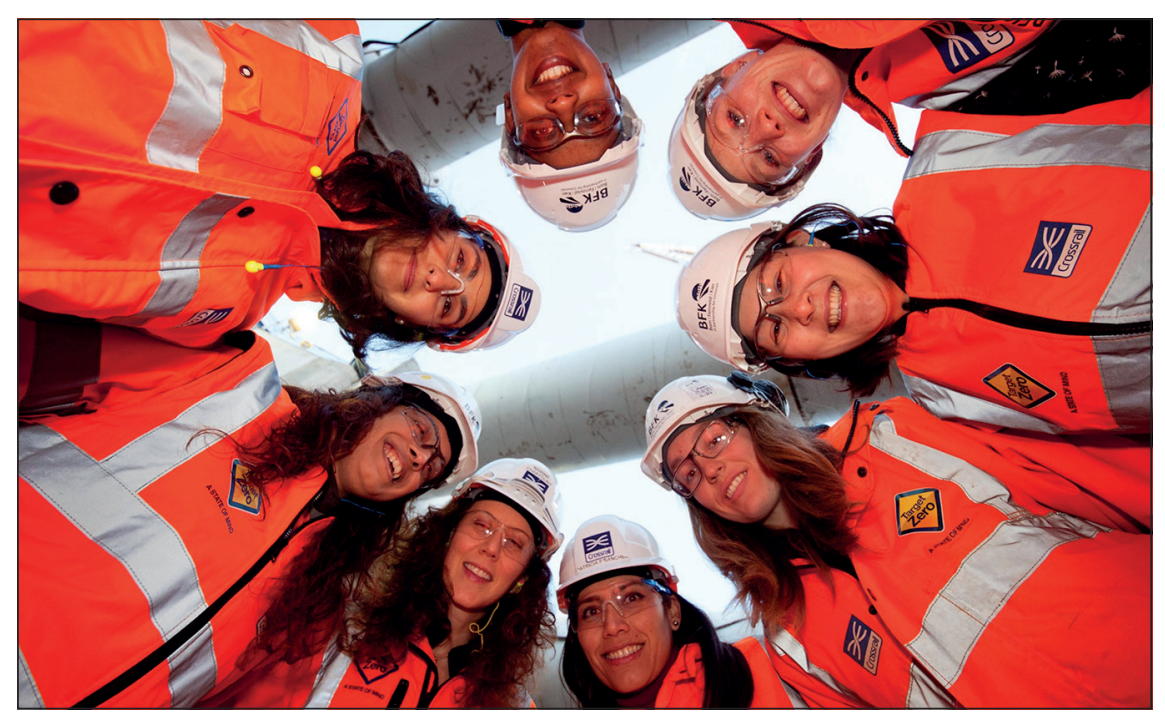

Figure 5. Female student and graduate applications to ICE are up to $21 \%$ 
This year's James Rennie Medal, which recognises the best chartered professional review candidate of the year, saw an all-female final. This is the first time in the medal's history that three women finalists have been selected from over 1000 candidates as being the best in the industry. Sonja, Victoria and Olivia between them have made some remarkable achievements, working on inspirational projects across the world. They symbolise how the face of the civil engineering industry is changing.

I hope it also shows that one day it will be possible to close down any remaining awards or schemes that are specifically for women, because there will not be any need for them. One day, I hope soon, women will automatically be reflected in all areas of the industry.

At the moment, however, the UK still has the lowest percentage of female engineers in Europe - less than 10\% across all disciplines. Latvia, Bulgaria and Cyprus have nearly 30\%. Everyone recognises that any organisation will be stronger if it can draw from a wealth of different experiences, and will better serve society if it reflects the diversity of the communities it serves. Engineering solutions are best delivered by multidisciplinary teams of men and women, from different ethnic backgrounds and sexual orientations, all working creatively together.

I am proud that ICE is leading by example. It is developing internship programmes for engineers returning to work after raising children. It is working with employers and schools to make sure the industry attracts talented people from all backgrounds. It is pushing on with ambitions to increase international membership by $10 \%$, year on year. In fact, two of my own president's apprentices this year are from outside the UK - based in Malaysia and the United Arab Emirates. And $50 \%$ of my apprentices are women, and they are not all from London and south-east England.

The Institution will continue to adopt ICE fellow Dawn Bonfield's philosophy, which is to be inclusive and think, 'I am not different from you; I am different like you'.
There are many people around the world who work day in, day out to deliver the infrastructure their communities need. And only some of them are civil engineers. I want ICE to play the greatest possible role in driving the transformation I have been describing. This means embracing all the professionals involved in civil engineering: colleagues from law, finance, environmental science, computer science - the list is endless.

This year ICE's council agreed to create a new associate membership to give all these colleagues a home at ICE. So a personal message from me: for those of you who want to be part of the Institution, but are not a practising civil engineer, you are most welcome to join - especially as the profession undertakes this new digital journey.

\section{Inventing the future of civil engineering}

I would like to conclude by stealing a phrase from someone who really did lead the way in innovative thinking. Steve Jobs said that if you want to be the future, you have to invent the future. To engineer a digital future, it means civil engineers have to invent their own future.

Now I recognise the cliché in using Apple as an example, but I do so because there is truth in it and it is perhaps the best example of what the profession should be trying to achieve. Apple did not just create a phone which used the latest technology, it created a new platform for innovation, with all the economic and social opportunities that have followed. The company's engineers were quite comfortable that even they did not understand its full potential.

When civil engineers build an infrastructure asset they should be equally open to the idea that they do not know with any certainty how it will be used in 25,50 or 100 years' time. This should give the profession an even bigger incentive to be inventive. If civil engineers want to develop smart, agile infrastructure that adapts to changing needs, then they need to think smart.
Civil engineers cannot transform the built environment without being transformative in their thinking. They cannot foster innovation in the profession without adopting innovative techniques. And they will not be able to meet society's changing expectations without using modern technology.

The profession has a fundamental opportunity - a fundamental responsibility - to help address this issue to help society thrive. ICE stands for shaping a better world - that is what civil engineers are about and why they are here. It is their job to push the construction industry to take on and deliver the difficult challenges. There is no agenda more difficult, or none that will define the profession for generations to come, than this one.

It will be hard, it will be disruptive change and it will certainly last longer than just my 1 year in office. It will be up to many of ICE's members to pick up that baton. Civil engineers need to commit wholeheartedly to making a digital future their priority.

That is what I, and ICE, plan to do over the next year.

\section{References}

Dobbs R, Pohl H, Lin DY et al. (2013) Infrastructure Productivity: How to Save \$1 Trillion a Year. McKinsey Global Institute, Seoul, South Korea. See http://www.mckinsey.com/ /media/ McKinsey/Industries/Capital\%20Projects\%20 and\%20Infrastructure/Our\%20Insights/ Infrastructure\%20productivity/MG|\%20 Infrastructure_Full\%20report_Jan\%202013.ashx (accessed 10/11/2016).

Farmer M (2016) The Farmer Review of the UK Construction Labour Model - Modernise or Die. Construction Leadership Council, London, UK. See http://www.cast-consultancy.com/newscasts/farmer-review-uk-construction-labourmodel-3/ (accessed 10/11/2016).

ICE (Institution of Civil Engineers) (2016) National Needs Assessment: A Vision for UK Infrastructure. ICE, London, UK. See https:// www.ice.org.uk/media-and-policy/policy/ national-needs-assessment-a-vision-for-ukinfrastr (accessed 10/11/2016).

KPMG (2016) Building a Technology Advantage - Global Construction Survey 2016. KPMG International, Amstelveen, the Netherlands. See https://assets.kpmg.com/content/dam/kpmg/xx/ pdf/2016/09/global-construction-survey-2016. pdf (accessed 10/11/2016).

The Daily Telegraph (2016) Top 50 women in engineering. The Daily Telegraph, 23 June. List republished at http://wes.org.uk/we50 (accessed 10/11/2016). 